\title{
A "lab-on-a-chip" experiment for assessing mineral reactivity in porous media: effects of hydrological heterogeneity
}

\author{
J. PoOnOOSAMY ${ }^{1}$, S. Roman ${ }^{2}$, C. Soulaine ${ }^{2}$, G. \\ DEISSMANN $^{1}$, D. BOSBACH ${ }^{1}$ \\ ${ }^{1} 1$ Institute of Energy and Climate Research (IEK-6): Nuclear \\ Waste Management and Reactor Safety, \\ Forschungszentrum Jülich GmbH, 52425 Jülich, \\ Germany,j.poonoosamy@ffz-juelich.de \\ ${ }^{2}$ Univ. Orléans, CNRS, BRGM, ISTO, UMR 7327, F-45071, \\ Orléans, France
}

The understanding of dissolution and precipitation of minerals and its impact on the transport of fluids in fractured media is essential for various subsurface applications. The implementation of such coupled processes into numerical reactive transport codes requires a mechanistic process understanding and model validation with quantitative experiments. In this context, we developed a microfluidic "lab-on-chip" of a reactive fractured porous medium of $800 \mu \mathrm{m} \times 900 \mu \mathrm{m}$ size with $10 \mu \mathrm{m}$ depth. The fractured medium consisted of compacted celestine grains (grain size $4-9 \mu \mathrm{m}$ ). A $\mathrm{BaCl}_{2}$ solution was injected into the microreactor at a flow rate of $500 \mathrm{nl} \mathrm{min}$, leading to the dissolution of celestine and an epitaxial growth of barite on its surface. Our investigations including confocal Raman spectroscopic techniques allowed for monitoring the temporal mineral transformation at the pore scale in $2 \mathrm{D}$ and 3D geometries. The fractured porous medium causes a heterogeneous flow field in the microreactor that leads to spatially different mineral transformation rates. The results of the ongoing microfluidic experiments in combination with advanced pore-scale modelling will provide new insights onto how hydrological heterogeneity may be an important factor contributing to the discrepancy between laboratory and field measured reaction rates. 